\title{
IDŐJÁRÁS
}

Quarterly Journal of the Hungarian Meteorological Service

Vol. 125, No. 3, July-September, 2021, pp. 463-476

\section{Impact of meteorological drought on vegetation in non-irrigated lands}

\section{Tahereh Sadat Mirmohammadhosseini ${ }^{1}$, Seyed Abbas Hosseini*1, Bagher Ghermezcheshmeh ${ }^{2}$, and Ahmad Sharafati ${ }^{1}$}

\author{
${ }^{1}$ Department of Civil Engineering \\ Science and Research Branch \\ Islamic Azad University, Tehran, Iran. \\ ${ }^{2}$ Soil Conservation and Watershed management institute \\ Agricultural Research, Education and Extension Organization (AREEO) \\ Tehran, Iran.
}

*Corresponding Author e-mail: abbas_hoseyni@srbiau.ac.ir

(Manuscript received in final form August 12, 2020)

\begin{abstract}
Drought is a natural phenomenon that causes a lot of damages annually in various sectors, including agriculture and natural resources. The aim of this study is to evaluate the influence of meteorological drought index on vegetation index. For this purpose, the standard precipitation index (SPI) as a meteorological drought index is calculated using the precipitation data of 28 meteorological stations located on the area of Lorestane province, Iran, during the years 1987-2017. Then, the vegetation condition index (VCI) is computed using normalized difference vegetation index (NDVI) images that obtained from MODIS images of Terra satellite during 2000-2017. Dry, normal, and wet years were obtained based on the SPI results for 2008, 2013, and 2016, respectively. SPI and VCI were correlated using Pearson's correlation method. The results of the relationship between VCI and SPI showed that the highest Pearson correlation coefficient related to 9month SPI in November was equal to 0.64. Multivariate linear regression was also performed between SPI and VCI, and the results showed that SPI was significantly correlated with VCI at 5\% level over a period of 9 and 12 months. Finally, a confusion matrix was used to evaluate the compliance of the SPI and VCI drought classes. Results showed that the VCI had the highest compliance in the moderate drought class with SPI.
\end{abstract}

Key-words: remote sensing, drought, standardized precipitation index, normalized difference vegetation index, vegetation condition index 


\section{Introduction}

Drought is one of the major natural hazards and can have significant environmental and economic effects. Compared to other natural hazards, such as floods and storms, the drought scope is generally much higher (Hagman et al., 1984; Wilhite and Vanyarkho, 2000). Therefore, forecasting drought can be a great help in reducing the damages that caused by it. Four categories of drought can be defined as meteorological drought, hydrological drought, agricultural drought, and economical drought (Heim Jr, 2002; Dai et al., 2004; Bates et al., 2008; Zhang et al., 2017; Agana and Homaifar, 2018). Reduction of precipitation causes meteorological drought, and a shortage of available water for plant growth results agricultural drought. Hydrological drought alludes to deficiency of the surface and subsurface water supply (Zhang and Jia, 2013; Zhang et al., 2017). Agricultural drought usually occurs after meteorological drought and before hydrological drought.

The first economic sector affected by drought is usually agriculture. Drought leads to a decrease in agricultural production, which is affected by the intensity, duration, and spatial extent of drought stresses (Dutta et al., 2015). Monitoring drought needs to be done to minimize such drought impacts. Different drought indices have been developed by a number of previous studies to determine the duration and severity of drought (Zargar et al., 2011). The standardized precipitation index (SPI) is a meteorological drought index that shows the level of drought due to rainfall deficit. The SPI introduced by McKee et al. (1993) has been widely used. For calculation of the SPI, the precipitation depth can be employed as an input variable, and it has been extensively used to define dry and wet conditions in many countries and regions (Guhathakurta et al., 2017; Hosseini et al., 2020). With the availability of different satellite data and the widespread use of them, it has become possible to study drought using this method (Dutta et al., 2015).

Studying the drought using remote sensing data has become possible with the availability of different satellite data and the widespread use of them. Using remote sensing indicators, the drought effects on plants and agriculture can be studied, and more accurate and effective results can be achieved for drought modeling (Heim Jr, 2002).

So far, many studies have been done on the extraction of drought indicators from satellite images, most of them show uncertainty that sometimes leads to the inefficiency of drought forecasting models. More careful selection and processing of images to extract indicators can increase their quality and ultimately lead to greater efficiency in drought forecasting models (Rhee et al., 2010).

Based on the studies, the relationship between the NDVI and SPI was investigated over three periods of 1, 3, and 6 months in Australia (Caccamo et al., 2011). The results showed that the highest correlation coefficient between NDVI and SPI was obtained at the 6 months period. 
In a similar study in the United States, among 1 to 12-month SPIs, the highest correlation coefficient was reported between the NDVI and 3-month SPI ( $J i$ and Peters, 2003).

There are important factors such as vegetation characteristics, the studied period, soil characteristics, and the distribution and intensity of rainfall that affect the occurrence of the highest correlation coefficient between NDVI and SPI (Moreira et al., 2008). The effectiveness of using the VCI in monitoring drought in different parts of the world has also been evaluated (Shahabfar et al., 2012).

There is a high correlation between the VCI that obtained from Advanced Very High Resolution Radiometer (AVHRR) images and agricultural production in South America, Africa, North America, Europe and Asia, especially, in the critical periods of growth (Singh et al., 2003).

Shad et al. (2017) examined the drought monitoring using vegetation indicators and MODIS data in Isfahan province. For this purpose they used 3month SPI and obtained Pearson correlation coefficients for the SPI index with NDVI, VCI, and TCI. The correlation coefficients showed that the NDVI and VCI can be good indices for monitoring drought in that region. Dutta et al. (2015) used long-term NDVI images to monitor agricultural drought. Comparison of SPI with VCI showed correlation coefficient value equal to 0.75 , which supported the efficiency of this remote sensing index to assess agricultural drought.

Zhang et al. (2017) concluded in their research that VCI can detect the onset of drought and the impact of it. The obvious advantage of VCI is the ease of calculation and the lack of need to view the station.

Previous studies indicate that there is a relationship between the meteorological drought and agricultural drought. Both types of drought are basically caused by a lack of rainfall, and agricultural drought occurs with a time lag from meteorological drought. The relationship between the two droughts varies according to location, climate, and morphometry. Another point is how these two droughts relate to each other, and this relationship may be linear or nonlinear and may be different for each region.

In this study, first the relationship between the meteorological and agricultural drought is investigated by using the SPI and VCI, then the time lag between occurrences of vegetation drought and meteorological drought in Lorestan province (western part of Iran) is examined, and also the rate of adaptation of drought classes for SPI and VCI is determined. Finally, based on the meteorological drought, vegetation drought is predicted.

In this research, non-irrigated vegetation of Lorestan province is considered to be studied because of being the dominant vegetation in that region. The results of this study will help farmers find out when the crop cultivation should be done according to the region's precipitation, in order to get a good harvest. 


\section{The study area and data used}

Lorestan province is located in the western part of Iran on the Zagros mountain range. The area is highly mountainous and covers about 28559 square kilometers. Most of the province's areas are covered by the Zagros Mountains. Fig. 1 shows the position of the studied area and the rain gauge stations located in this area.

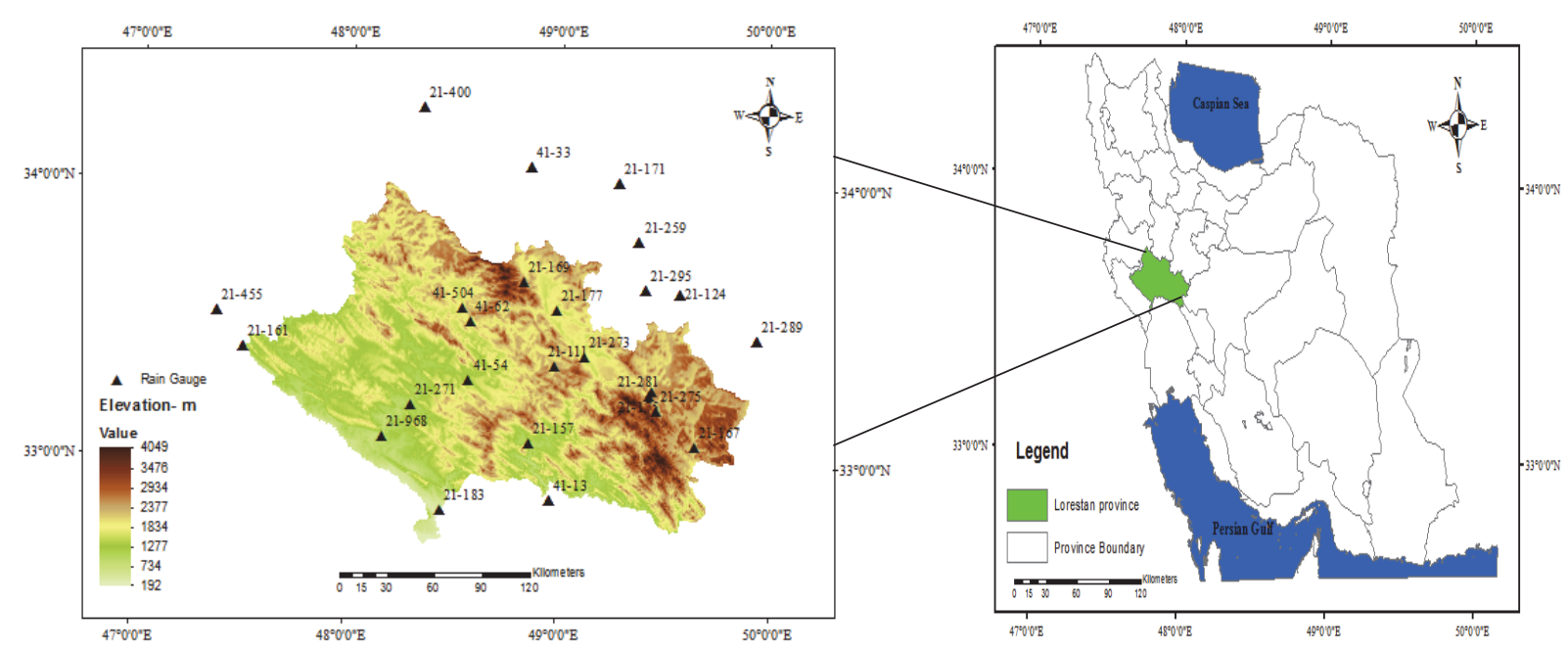

Fig 1. Geographic location of the studied area along with selected rain gauge stations

Lorestan is a highly elevated province with different climates, changing from north to south and from east to west. The maximum recorded temperature in the province is $+47.4{ }^{\circ} \mathrm{C}$ and the minimum is $-35^{\circ} \mathrm{C}$. The average annual precipitation is $550 \mathrm{~mm}$. For this study, the monthly rainfall data of 28 rain gauge stations located in and around the province were used. The stations were selected based on the length of the statistical period, appropriate spatial coverage and statistical accuracy in Lorestan province, and on the reliability of their statistical data. The time period studied in this study was considered from 1987 to 2017. The data were collected from the ministry of water and power of the country. The data quality analysis was performed using the double mass curve method, and it was revealed that the database is homogeneous. The missing data gaps were filled using a regression method and by considering high determination coefficients with the nearest suitable station. Table 1 shows the specifications of the selected stations. 
Table1. Specifications of the selected stations

\begin{tabular}{|c|c|c|c|c|c|}
\hline No. & $\begin{array}{c}\text { Station } \\
\text { name }\end{array}$ & $\begin{array}{c}\text { Station } \\
\text { code } \\
\end{array}$ & $\begin{array}{c}\text { Latitude } \\
\text { (degree) } \\
\end{array}$ & $\begin{array}{l}\text { Longitude } \\
\text { (degree) }\end{array}$ & $\begin{array}{c}\text { Elevation } \\
(\text { m.a.s.l) } \\
\end{array}$ \\
\hline 1 & Afrineh & $21-177$ & 33.31 & 47.89 & 820 \\
\hline 2 & Aghjanbolaghi & $21-111$ & 34.85 & 48.05 & 1803 \\
\hline 3 & Alraj & $21-504$ & 34.12 & 49.32 & 1870 \\
\hline 4 & Astaneh & $41-54$ & 33.89 & 49.36 & 2060 \\
\hline 5 & Aznacham & $21-271$ & 33.40 & 49.40 & 1830 \\
\hline 6 & Chamanjir & $21-175$ & 33.44 & 48.25 & 1140 \\
\hline 7 & Chamchit & $21-281$ & 33.56 & 48.98 & 1290 \\
\hline 8 & Daretakht & $21-275$ & 33.58 & 49.38 & 1940 \\
\hline 9 & Dartoot & $21-157$ & 33.74 & 46.65 & 907 \\
\hline 10 & Dehnu & $21-167$ & 33.52 & 48.78 & 1770 \\
\hline 11 & Emarat & $41-959$ & 33.87 & 49.58 & 2100 \\
\hline 12 & Ghahavand & $41-62$ & 34.86 & 49.00 & 1625 \\
\hline 13 & Ghelyan & $21-968$ & 33.05 & 49.38 & 1750 \\
\hline 14 & Kakareza & $21-169$ & 33.72 & 48.25 & 1530 \\
\hline 15 & Kamandan & $21-273$ & 33.31 & 49.43 & 2080 \\
\hline 16 & Kazemabad & $21-400$ & 33.13 & 49.68 & 2000 \\
\hline 17 & Khandab & $41-33$ & 34.40 & 49.18 & 1650 \\
\hline 18 & Kheiabad & $21-32$ & 34.47 & 48.62 & 1763 \\
\hline 19 & Khomein & $41-13$ & 33.64 & 40.07 & 1800 \\
\hline 20 & Poldokhtar & $21-183$ & 33.16 & 47.71 & 650 \\
\hline 21 & Polezal & 21-189 & 32.81 & 48.08 & 300 \\
\hline 22 & Sarab & $21-171$ & 33.79 & 48.20 & 1520 \\
\hline 23 & Sazmanab & $21-124$ & 33.78 & 48.80 & 1490 \\
\hline 24 & Sorkhab & $21-289$ & 33.14 & 48.63 & 770 \\
\hline 25 & Talezang & $21-295$ & 32.87 & 48.77 & 440 \\
\hline 26 & Vanayi & $21-259$ & 33.91 & 48.59 & 2000 \\
\hline 27 & Vargach & $21-161$ & 33.57 & 46.82 & 783 \\
\hline 28 & Zoorabad & $21-455$ & 32.06 & 48.57 & 42 \\
\hline
\end{tabular}

\section{Methodology}

\subsection{Standardized precipitation index (SPI)}

SPI was introduced by McKee in 1993 based on the probability of precipitation for each time period (McKee et al., 1993). It can be calculated for different ranges 
(Mishra et al., 2009). SPI is computed by fitting the gamma density function on the distribution of rainfall frequency for a given station, and the cumulative distribution function is turned into the standard normal distribution (with mean zero and variance of unity) via equal probabilities. The classification of the SPI were proposed by Mckee et al. (1993) according to Table 2.

Table 2. Drought classification based on SPI values (Mckee et al., 1993)

\begin{tabular}{cc}
\hline \hline SPI Value & Classification \\
\hline \hline$\geq 2$ & Extreme wet \\
$(1.5)-(1.99)$ & Very wet \\
$(1.0)-(1.49)$ & Moderate wet \\
$(0.99)-(-0.99)$ & Normal \\
$(-1.0)-(-1.49)$ & Moderate drought \\
$(-1.5)-(-1.99)$ & Severe drought \\
$\leq-2$ & Extreme drought \\
\hline
\end{tabular}

\subsection{Remote sensing data}

\subsubsection{Normalized difference vegetation index (NDVI)}

The normalized difference vegetation index (NDVI) is an index of plant greenness or photosynthetic activity, and it is one of the most commonly used vegetation indices (Bhandari et al., 2012; Vrieling et al., 2013; Zhu et al., 2013; Choubin et al., 2019; Viana et al., 2019). Vegetation indices are based on the observation that different surfaces reflect different types of light differently. A photosynthetically active vegetation, in particular, absorbs most of the red light that hits it while reflecting much of the near infrared light. NDVI is calculated based on the following equation:

$$
\mathrm{NDVI}=(\mathrm{NIR}-\mathrm{R}) /(\mathrm{NIR}+\mathrm{R}),
$$

where the NIR is the infrared band and R is the red band, and the band number is obtained in different satellite images. Images of the monthly MODIS-NDVI time series (MODIS-13) used in this study were taken from the Terra satellite for the years 2000 to 2017 . Data from this index were used at 16-day intervals at a resolution of 250 meters. 


\subsubsection{Vegetation condition index (VCI)}

Vegetation condition index (VCI) was first obtained by Kogan in 1995 based on NDVI images to eliminate the effect of climatic and topographic differences (Kogan, (1995). This index is defined according to the following equation:

$$
\mathrm{VCI}=\frac{\mathrm{NDVI}_{\mathrm{j}}-\mathrm{NDVI}_{\min }}{\mathrm{NDVI}_{\max }-\mathrm{NDVI}_{\min }} \times 100
$$

where $\mathrm{NDVI}_{\max }$ and $\mathrm{NDVI}_{\min }$ represent maximum and minimum NDVI of each pixel calculated for each month and $\mathrm{j}$ represents the index of the current month.

The results of VCI are better than the NDVI in terms of rainfall, especially in areas that are geographically heterogeneous. Using the time series data of the NDVI that extracted, the vegetation condition index (VCI) time series data were calculated based on Eq. (2).

\subsection{Non-irrigated lands extraction}

By using the Google Earth satellite imagery feature, the range of non-irrigated lands in Lorestan province was extracted and then about 200 points were determined on the areas that were extracted as non-irrigated lands. NDVI and VCI values for each of the 200 points were extracted using the GIS software. By using SPI calculated for 28 stations, SPI values were interpolated by the inverse distance weighting (IDW) method for the rest of the province. Thus, SPI were obtained for every 200 extracted points. It should be noted that these points were selected in such a way that at a distance of at least 500 meters, their use is completely nonirrigated, thus VCI index cells are completely pure non-irrigated and do not interfere with other uses.

\subsection{The confusion matrix of meteorological drought index and vegetation}

In this study, the degree of compatibility of drought classes between the meteorological and agricultural drought was examined using a confusion matrix, and it was showed, which class of these two droughts have a higher compatibility with each other during drought occurrences. Therefore, in order to use this matrix, it is necessary to make the same classification between the SPI and VCI. For this purpose, drought classification for both indices was performed in five classes based on Table 3. 
Table 3: Classification of the SPI and VCI values (Kogan, 2001)

\begin{tabular}{cccc}
\hline \hline Class No. & SPI & Classification & VCI \\
\hline \hline 1 & $\leq-1 / 5$ & Extreme & $<20$ \\
2 & $-1 / 5<\mathrm{SPI}<0$ & Moderate & $20-40$ \\
3 & $0<\mathrm{SPI}<1$ & Normal & $40-60$ \\
4 & $1<\mathrm{SPI}<1 / 5$ & Moderate wet & $60-70$ \\
5 & $\geq 1 / 5$ & Severe wet & $70<$ \\
\hline
\end{tabular}

\section{Results and discussions}

Using monthly precipitation data from 28 rain gauge stations, the 1, 3, 6, 9, and 12-month SPIs from 1987 to 2017 were calculated. The SPI chart against the year was drawn for each of the stations. SPI changes range from -2 to +2 , with negative values indicating dry years and positive values indicating wet years. Drought fluctuations are greater in the short term compared to the long term.

According to the calculated SPIs, the year, in which the SPI values were negative and covered the entire area of the region, and also the year before and after that was usually in the dry period, was considered to determine the representative of the dry year. Similarly, the year in which the SPI values were positive and covered the entire area of the region, and also the year before and after that was usually in the wet period, was considered to determine the representative of the wet year. For the normal year, the year, in which the SPI values were between -0.99 and 0.99 , and the year before and after that was in the normal year period was considered as the representative of the normal year. Thus, 2008, 2013, and 2016 were considered as dry, normal, and wet years, respectively. Fig. 2 shows the SPI and VCI classification maps for 2008, 2013 and 2016. 
a)
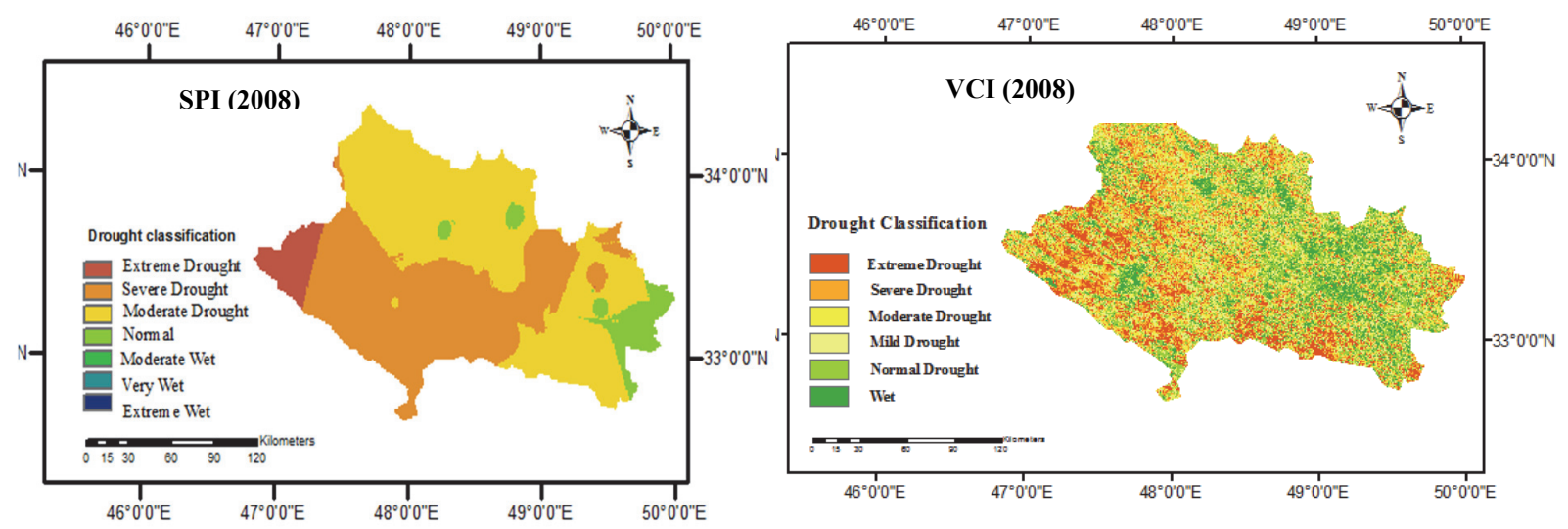

b)
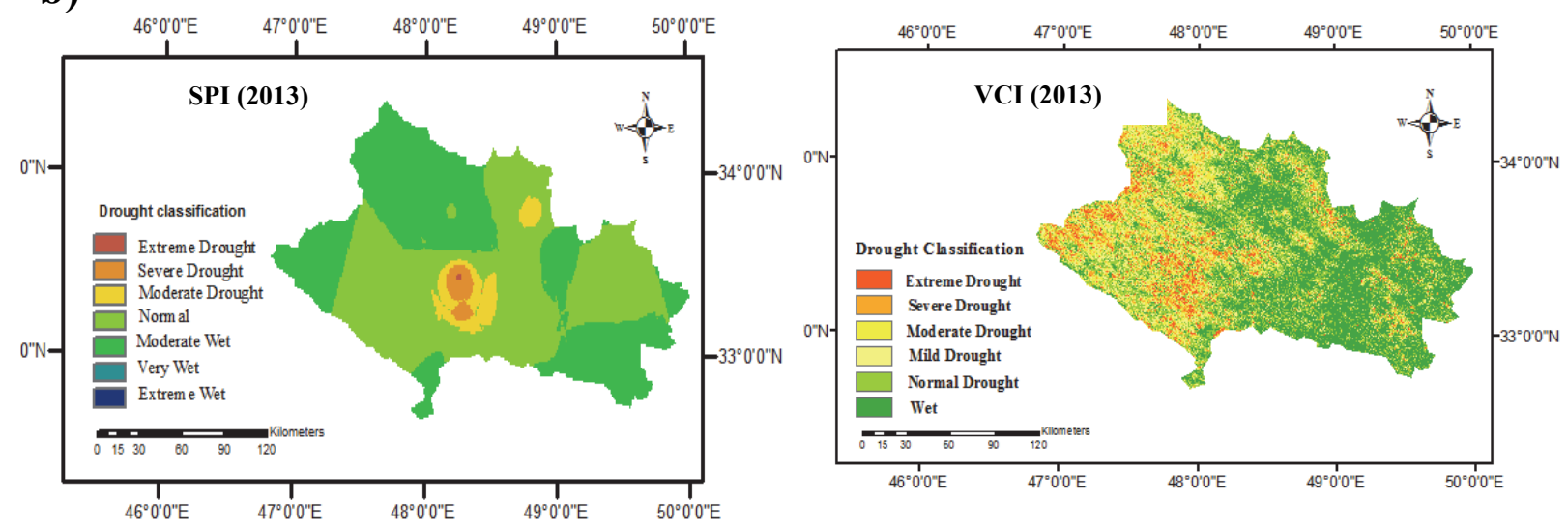

c)
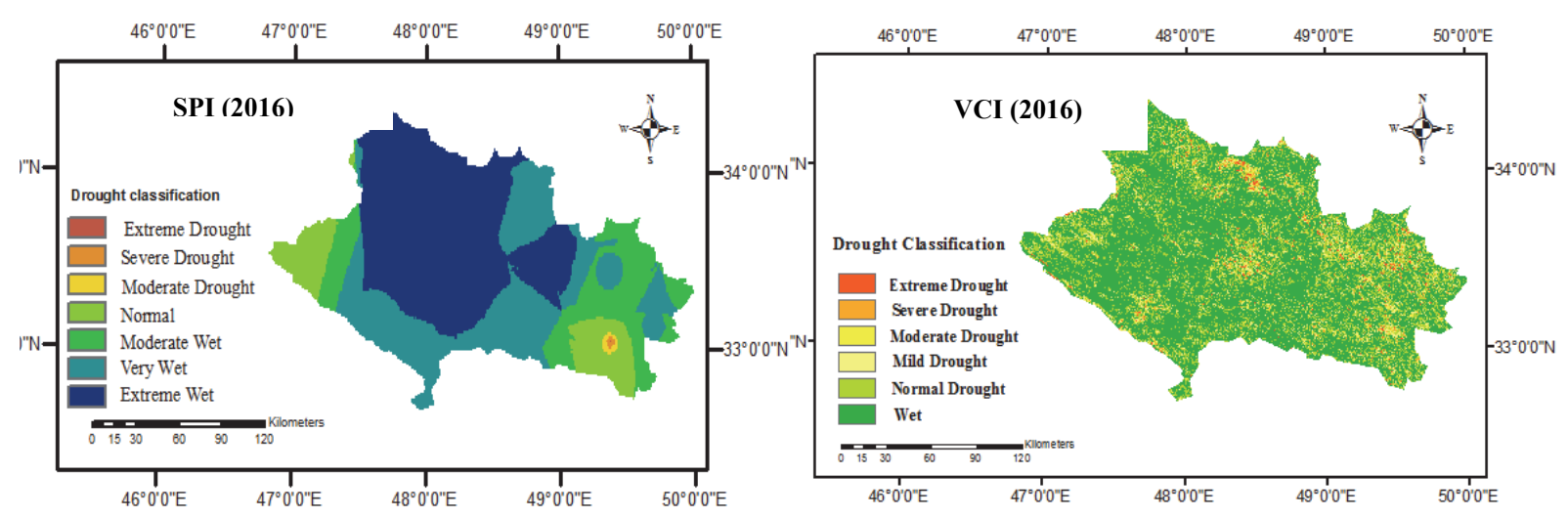

Fig. 2. SPI and VCI classification maps in Lorestan province in the years: a) 2008, b) 2013, and c) 2016 .

The Pearson correlation coefficient was used to investigate the relationship between SPI and VCI. For this purpose, the correlation between SPI and VCI was 
calculated for three years $(2008,2013$, and 2016). The Pearson correlation coefficients were calculated between SPI values for the months (January, February, March, April, May June, October, and December), and VCI during the growth period (March, April, May, and June) for 200 selected points in nonirrigated land. Also, a multivariate linear regression was performed between SPI and VCI to obtain the best relationship between SPI with different time series and $\mathrm{VCI}$ by the correlation coefficient between them.

The results of the correlation between the VCI in March and SPI showed that in 2008, the highest correlation coefficient was related to the 9-month SPI in November by a value of 0.64 . Also, in the same year, the highest correlation coefficient of multivariate linear regression was related to the 9 and 12-month SPI and was equal to 0.55 . It shows that the value of this correlation increases at the beginning of the growing season. Table 4 Correlation coefficients between VCI in March and SPI in 2008.

Table 4. Correlation coefficients between VCI in March and SPI in 2008

\begin{tabular}{lcccccccccc}
\hline \hline \multicolumn{1}{c}{ SPI } & Apr & May & Jun & Oct & Nov & Dec & Jan & Feb & Mar & $\begin{array}{c}\text { Multi } \\
\text { regression }\end{array}$ \\
\hline \hline SPI 1 & -0.17 & 0.33 & 0.19 & 0.16 & 0.35 & 0.33 & 0.1 & 0.22 & 0.22 & 0.37 \\
SPI 3 & 0.15 & 0.25 & 0.25 & 0.29 & 0.36 & 0.37 & 0.32 & -0.21 & -0.16 & 0.38 \\
SPI 6 & 0.27 & -0.29 & 0.27 & 0.11 & 0.36 & 0.37 & 0.32 & 0.33 & 0.30 & 0.45 \\
SPI 9 & 0.50 & 0.50 & 0.31 & 0.51 & $\mathbf{0 . 6 4}$ & 0.47 & 0.51 & 0.52 & 0.51 & $\mathbf{0 . 5 5}$ \\
SPI 12 & 0.50 & 0.51 & 0.51 & 0.53 & 0.52 & 0.29 & 0.34 & 0.39 & 0.43 & $\mathbf{0 . 5 5}$ \\
\hline
\end{tabular}

Also, the correlation results that obtained from the relationship between VCI in April, May, and June with SPI showed that the highest correlation coefficient for multivariate regression is related to the 9 and 12-month SPI and is equal to $0.57,0.62$, and 0.75 , respectively.

Table 5 shows the correlation coefficients between the 9 and 12-month SPI and VCI in April, May, and June.

Table 5. Correlation coefficients between the 9 and 12-month SPI and VCI in April, May, and June in 2008

\begin{tabular}{cccc}
\hline VCI & SPI9 & SPI12 & Multi regression \\
\hline \hline April & 0.5 & 0.41 & 0.57 \\
May & 0.56 & 0.59 & 0.62 \\
June & 0.61 & 0.55 & 0.75 \\
\hline
\end{tabular}


According to Table 5, the highest correlation coefficient between SPI and VCI in March, April, May, and June was observed for VCI in June. The results of the previous research showed that the highest correlation coefficient between SPI and vegetation index is related to the 9-month SPI (Liu et al., 2020). Yagci et al. (2015) also observed a good correlation between VCI and SPI values, and VCI was introduced as a suitable index for using in the product value prediction model along with NDVI.

The results of the present study showed that the correlation coefficient for multivariate linear regression (April, May, June, October, October, November, and December) has higher value than that of the single-variable regression of each month.

Eq. (3) presents the regression, in which the significance level of the F test is less than 0.05, indicating that the regression model was appropriate and the SPI values have been able to significantly predict changes in the VCI and to affect VCI.

$$
\begin{aligned}
& \mathrm{VCI}(\text { June })=1.4 \mathrm{SPI}(\text { April })+0.46 \mathrm{SPI} \text { (May) }-0.63 \mathrm{SPI}(\text { June })+0.09 \text { SPI } \\
& \text { (October) }-0.27 \text { SPI (November) }-1.15 \text { SPI (December })+0.87 \text {. }
\end{aligned}
$$

The results of the confusion matrix for the 9-month SPI in November and the VCI in June are presented in Table 6. According to this table, the highest compatibility between these two indices occured in moderate drought conditions.

Table 6. Confusion matrix for 9-months SPI in November and VCI in June

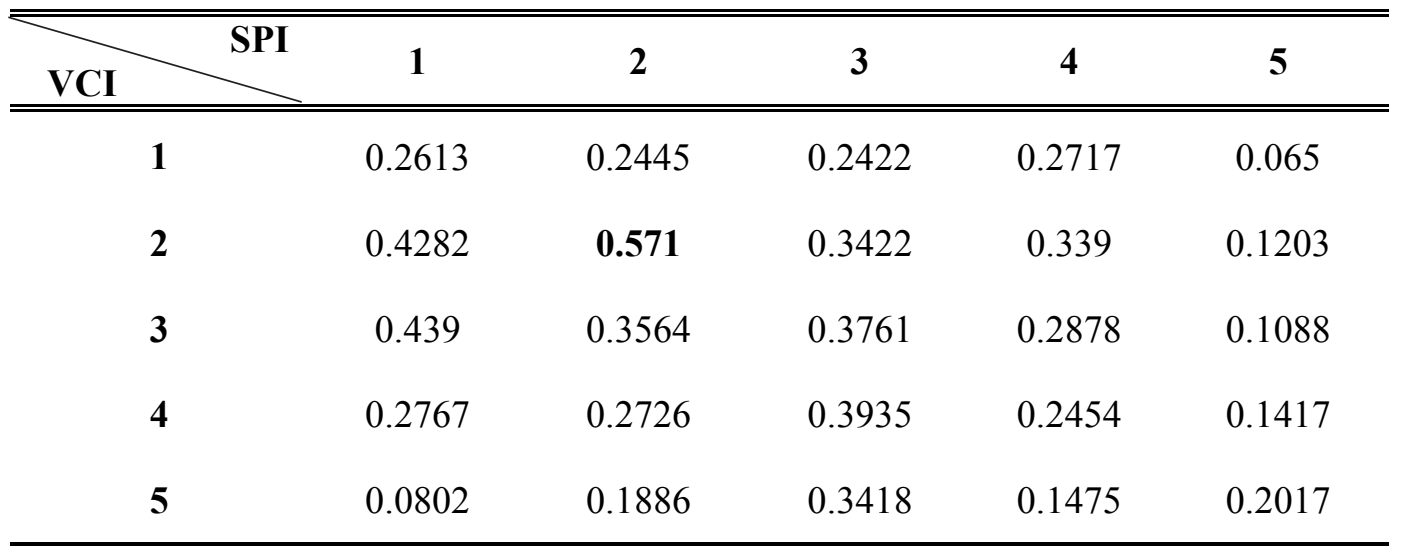




\section{Conclusions}

In the present study, meteorological data and remote sensing data were used to investigate the effect of meteorological drought on agricultural drought and their relationship. First, the SPI index for 28 rain gauge stations of Lorestan province was calculated for the years from 1987 to 2017. Then, by using NDVI images that extracted from Terra MODIS, the VCI was calculated and finally the relationship between SPI and VCI was examined.

According to the results of SPI, for Lorestan province, dry, normal, and wet years were selected in 2008, 2013, and 2016, respectively.

The results obtained from the investigation of the relationship between SPI and VCI showed that the highest correlation coefficient of VCI was for the 9-month SPI in November. Based on the previous studies, there was a good correlation between SPI and VCI (Dutta et al., 2015), which confirms the results of this study.

It should be noted that in the growing season of vegetation cover, VCI calculation is faced with less error and the correlation between SPI and VCI is higher.

Due to the different environmental and climatic conditions and vegetation, similar results cannot be expected in different regions and the relationship between each of the agricultural drought indicators that extracted from satellite images should be studied separately in each region. Depending on the specific climatic conditions and vegetation, it is necessary to select the appropriate index for monitoring agricultural drought for each region.

According to the results of multivariate regression between SPI and VCI, the correlation coefficient between the 9 and 12-months is higher than other time series, which indicates that non-irrigated products in November are dependent on the rainfall of 9 or 12 months ago.

According to the results, due to the fact that the growth of the crop is faster in the two months of May and June, if the crop faced with a lack of rainfall, the study of VCI in these two months is more important than in other months.

In the equation which resulted from the regression of VCI with SPI, the significance level of $\mathrm{F}$ test was less than 0.05 , which indicates that the regression model is appropriate and SPI variables in different months have been able to predict the changes of VCI variables and affect them. The results of the confusion matrix showed that the VCI was most compatible with SPI in the average moderate drought class. 


\section{References}

Agana, N.A. and Homaifar, A., 2018: EMD-based predictive deep belief network for time series prediction: an application to drought forecasting. Hydrology, 5, 18. https://doi.org/10.3390/hydrology5010018

Bates, B.C., Kundzewicz, Z.W., Wu, S., and Palutikof, J.P., 2008: Climate Change and Water. Paper of the Intergovernmental Panel on Climate Change. IPCC Secretariat: Geneva.

Bhandari, A.K., Kumar, A., and Singh, G.K., 2012: Feature extraction using Normalized Difference Vegetation Index (NDVI): A case study of Jabalpur city. Procedia Technology 6, 612-621. https://doi.org/10.1016/j.protcy.2012.10.074

Caccamo, G., Chisholm, L.A., Bradstock, R.A., and Puotinen, M.L., 2011: Assessing the sensitivity of MODIS to monitor drought in high biomass ecosystems. Remote Sens. Environ. 115, 2626-2639. https://doi.org/10.1016/j.rse.2011.05.018

Choubin, B., Soleimani, F., Pirnia, A., Sajedi-Hosseini, F., Alilou, H., Rahmati, O., Melesse, A.M., Singh, V.P., and Shahabi, H., 2019: Effects of drought on vegetative cover changes: Investigating spatiotemporal patterns, In: Extreme Hydrology and Climate Variability. Elsevier, 213-222. https://doi.org/10.1016/B978-0-12-815998-9.00017-8

Dai, A., Trenberth, K.E., and Qian, T., 2004: A global dataset of Palmer Drought Severity Index for 1870-2002: Relationship with soil moisture and effects of surface warming. J. Hydrometeorol. 5, 1117-1130. https://doi.org/10.1175/JHM-386.1

Dutta, D., Kundu, A., Patel, N.R., Saha, S.K., and Siddiqui, A.R., 2015: Assessment of agricultural drought in Rajasthan (India) using remote sensing derived Vegetation Condition Index (VCI) and Standardized Precipitation Index (SPI). Egyptian J. Remote Sens.Space Sci. 18, 53-63. https://doi.org/10.1016/j.ejrs.2015.03.006

Guhathakurta, P., Menon, P., Inkane, P.M., Krishnan, U., and Sable, S.T., 2017: Trends and variability of meteorological drought over the districts of India using standardized precipitation index. $J$. Earth Syst. Sci. 126. https://doi.org/10.1007/s12040-017-0896-x

Hagman, G., Beer, H., Bendz, M., and Wijkman, A., 1984: Prevention better than cure. Report on human and environmental disasters in the Third World. 2.

Heim Jr, R.R., 2002: A review of twentieth-century drought indices used in the United States. Bull. Amer. Meteorol. Soc. 83, 1149-1166. https://doi.org/10.1175/1520-0477-83.8.1149

Hosseini, T.S.M., Hosseini, S.A., Ghermezcheshmeh, B., and Sharafati, A., 2020: Drought hazard depending on elevation and precipitation in Lorestan, Iran. Theor. Appl. Climatol. 142, 1369-1377. https://doi.org/10.1007/s00704-020-03386-y

$J i, L$. and Peters, A.J., 2003: Assessing vegetation response to drought in the northern Great Plains using vegetation and drought indices. Remote Sens. Environ. 87, 85-98. https://doi.org/10.1016/S0034-4257(03)00174-3

Kogan, F.N., 1995: Application of vegetation index and brightness temperature for drought detection. Adv. Space Res. 15, 91-100. https://doi.org/10.1016/0273-1177(95)00079-T

Kogan, F.N., 2001: Operational space technology for global vegetation assessment. Bull. Amer. Meteorol. Soc. 82, 1949-1964. https://doi.org/10.1175/1520-0477(2001)082<1949:OSTFGV>2.3.CO;2

Liu, Q., Zhang, S., Zhang, H., Bai, Y., and Zhang, J., 2020: Monitoring drought using composite drought indices based on remote sensing. Sci. Total Environ. 711, 134585.

Mckee, T.B., Doesken, N.J., and Kleist, J., 1993: The relationship of drought frequency and duration to time scales. AMS 8th Conference on Applied Climatology, 179-184. doi:citeulike-articleid: 10490403

Mishra, A.K., Singh, V.P., and Desai, V.R., 2009: Drought characterization: a probabilistic approach. Stoch. Environ. Res. Risk Assess. 23, 41-55. https://doi.org/10.1007/s00477-007-0194-2

Moreira, E.E., Coelho, C.A., Paulo, A.A., Pereira, L.S., and Mexia, J.T., 2008: SPI-based drought category prediction using loglinear models. J. Hydrol. 354, 116-130. https://doi.org/10.1016/j.jhydrol.2008.03.002

Rhee, J., Im, J., and Carbone, G.J., 2010: Monitoring agricultural drought for arid and humid regions using multi-sensor remote sensing data. Remote Sens. Environ. 114, 2875-2887.

https://doi.org/10.1016/j.rse.2010.07.005 
Shad, M.S., Ildoromi, A., and Akhzari, D., 2017: Drought Monitoring Using Vegetation Indices and MODIS Data (Case Study: Isfahan Province, Iran). J. Rangeland Sci. 7, 148-159.

Shahabfar, A., Ghulam, A., and Eitzinger, J., 2012: Drought monitoring in Iran using the perpendicular drought indices. Int. J. of Appl. Earth Observ. Geoinf. 18, 119-127.

https://doi.org/10.1016/j.jag.2012.01.011

Singh, R.P., Roy, S., and Kogan, F., 2003: Vegetation and temperature condition indices from NOAA AVHRR data for drought monitoring over India. Int. J. Remote Sens. 24, 4393-4402. https://doi.org/10.1080/0143116031000084323

Viana, C.M., Oliveira, S., Oliveira, S.C., and Rocha, J., 2019: Land use/land cover change detection and urban sprawl analysis, In: Spatial Modeling in GIS and R for Earth and Environmental Sciences. Elsevier, 621-651. https://doi.org/10.1016/B978-0-12-815226-3.00029-6

Vrieling, A., De Leeuw, J., and Said, M.Y., 2013: Length of growing period over Africa: Variability and trends from 30 years of NDVI time series. Remote Sens. 5, 982-1000. https://doi.org/10.3390/rs5020982

Wilhite, D.A. and Vanyarkho, O. V, 2000: Drought: Pervasive impacts of a creeping phenomenon.

Yagci, A.L., Di, L., and Deng, M., 2015: The effect of corn-soybean rotation on the NDVI-based drought indicators: A case study in Iowa, USA, using vegetation condition index. GISci. Remote Sens. 52, 290-314. https://doi.org/10.1080/15481603.2015.1038427

Zargar, A., Sadiq, R., Naser, B., and Khan, F.I., 2011: A review of drought indices. Environmental Reviews, 19, 333-349. https://doi.org/10.1139/a11-013

Zhang, A. and Jia, G., 2013: Monitoring meteorological drought in semiarid regions using multi-sensor microwave remote sensing data. Remote Sens. Environ. 134, 12-23. https://doi.org/10.1016/j.rse.2013.02.023

Zhang, L., Jiao, W., Zhang, H., Huang, C., and Tong, Q., 2017: Studying drought phenomena in the Continental United States in 2011 and 2012 using various drought indices. Remote Sens. Environ. 190, 96-106. https://doi.org/10.1016/j.rse.2016.12.010

Zhu, Z., Bi, J., Pan, Y., Ganguly, S., Anav, A., Xu, L., Samanta, A., Piao, S., Nemani, R.R., and Myneni, R.B., 2013: Global data sets of vegetation leaf area index (LAI) $3 \mathrm{~g}$ and fraction of photosynthetically active radiation (FPAR) $3 \mathrm{~g}$ derived from global inventory modeling and mapping studies (GIMMS) normalized difference vegetation index (NDVI3g) for the period 1981 to. Remote Sens. 5, 927-948. https://doi.org/10.3390/rs5020927 